\title{
Halogen adsorbates on polymer-stabilized gold clusters: Mass spectrometric detection and effects on catalysis
}

\author{
Ryo Ishida a, Setsuka Arii a, Wataru Kurashige b, Seiji Yamazoe a,c, Kiichirou Koyasu a,c, \\ Yuichi Negishi b, Tatsuya Tsukuda a,c,* \\ a Department of Chemistry, School of Science, The University of Tokyo, 7-3-1 Hongo, Bunkyoku, Tokyo 113-0033, Japan \\ b Department of Applied Chemistry, Faculty of Science, Tokyo University of Science, 1-3 Kagurazaka, Shinjuku-ku, Tokyo 162-8601, Japan \\ c Elements Strategy Initiative for Catalysts and Batteries (ESICB), Kyoto University, Katsura, Kyoto 615-8520, Japan
}

\section{A R T I C L E I N F O}

\section{Article history:}

Received 6 May 2016

Accepted 15 June 2016

Published 5 October 2016

\section{Keywords:}

Gold cluster

Poly( $N$-vinyl-2-pyrrolidone)

Halogen adsorbates

Aerobic alcohol oxidation

Mass spectrometry

\begin{abstract}
A B S T R A C T
The mass spectrometry of gold clusters stabilized by poly( $N$-vinyl-2-pyrrolidone) (Au:PVP) revealed the presence of $\mathrm{Cl}$ adsorbates derived from synthetic precursors, mainly on the $\mathrm{Au}_{34}$ and $\mathrm{Au}_{43}$ clusters. Changes in the amount of $\mathrm{Cl}$ adsorbates on the Au clusters did not affect the catalytic properties for the aerobic oxidation of benzyl alcohol, suggesting that the $\mathrm{Cl}$ atoms were only weakly bound to the $\mathrm{Au}$ clusters. In contrast, the replacement of $\mathrm{Cl}$ with $\mathrm{Br}$ on the $\mathrm{Au}_{34}$ and $\mathrm{Au}_{43}$ clusters significantly suppressed activity, without any influence on the electronic structure. This result indicated that the $\mathrm{Br}$ atoms were strongly bound to the Au clusters and sterically blocked their active sites. The substantial reduction of the catalytic activity by the $\mathrm{Br}$ adsorbates suggested that the $\mathrm{Au}_{34}$ and $\mathrm{Au}_{43}$ clusters made a major contribution to the catalytic activity of the Au:PVP.
\end{abstract}

C 2016, Dalian Institute of Chemical Physics, Chinese Academy of Sciences. Published by Elsevier B.V. All rights reserved.
The catalysis of nano-sized gold has attracted growing interest, both in academia and industry, since the discovery of the catalysis of $\mathrm{CO}$ oxidation by heterogeneous Au catalysts [1]. It is widely accepted that the diameter of the Au catalysts is the most important structural parameter governing the catalytic performance [2-4]. We reported previously that the catalytic activity of $\mathrm{Au}$ nanoparticles stabilized by poly( $N$-vinyl-2-pyrrolidone) (PVP) emerged when the particle diameter was below $\sim 4 \mathrm{~nm}$; the catalytic activity dramatically increased as the diameter decreased $[5,6]$. This size-specific catalysis indicated that Au clusters smaller than $2 \mathrm{~nm}$ might be promising candidates for active catalysts [6,7]. Another important factor for catalysis is the interaction between the Au clusters and the solid supports or polymers used for stabilization. For example, we demonstrated that PVP played an essential role in activating the Au clusters by donating electronic charge when it is used as a stabilizer [8]. Recently, we also showed that the residual thiolates on $\mathrm{Au}$ clusters supported on porous carbon enhanced the selectivity in the aerobic oxidation of alcohols with some reduction in the activity [9]. This phenomenon was explained in terms of the steric hindrance and modulation of the electronic structures by the thiolate ligands. As opposed to poisoning, the catalytic activity of metal clusters can be enhanced by ligation, as recently reported for the hydrolytic oxidation of organosilanes by alkyne-protected AuAg alloy clusters [10]. During the mass-spectrometric characterization of Au:PVP, we unexpectedly found that $\mathrm{Cl}$ atoms derived from a gold precursor $\left(\mathrm{AuCl}_{4}^{-}\right)$were adsorbed on the Au clusters. Motivated by

\footnotetext{
* Corresponding author. Tel/Fax: +81-3-5841-4363; E-mail: tsukuda@chem.s.u-tokyo.ac.jp

This work was supported by the Elements Strategy Initiative for Catalysts and Batteries (ESICB) and a Grant-in-Aid for Scientific Research (26248003, 15H01042) from the Ministry of Education, Culture, Sports, Science and Technology (MEXT) of Japan. DOI: 10.1016/S1872-2067(16)62501-9 | http://www.sciencedirect.com/science/journal/18722067 | Chin. J. Catal., Vol. 37, No. 10, October 2016
} 
this finding, we studied the effect of the previously overlooked halogens on the catalysis of Au clusters.

$\mathrm{Au}: \mathrm{PVP}$ clusters were prepared using a microfluidic mixer as follows [11]. First, two solutions (A and $\mathbf{B}$ ) were prepared by mixing two aqueous solutions at $273 \mathrm{~K}$ : aqueous solutions of PVP (666.6 mg in $20 \mathrm{~mL}$ ) and $\mathrm{HAuCl}_{4}$ (30 mmol/L, $10 \mathrm{~mL}$ ) were mixed to produce solution $\mathbf{A}$, and aqueous solutions of PVP (666.6 mg in $25 \mathrm{~mL}$ ) and $\mathrm{NaBH}_{4}(56.7 \mathrm{mg}, 5 \mathrm{~mL}$ ) were mixed to produce solution B. Solutions A and $\mathbf{B}$ were then loaded into two syringes and injected into the micromixer (SIMM-V2, Institut für Mikrotechnik Mainz $\mathrm{GmbH}$ ) placed in an ice bath, using automatically actuated syringe pumps. Both syringe pumps were activated simultaneously, using a constant flow rate of $200 \mathrm{~mL} / \mathrm{h}$. The eluted solution was collected, and then stirred at $273 \mathrm{~K}$ for $1 \mathrm{~h}$. Subsequent deionization of the obtained hydrosol via ultrafiltration yielded Au:PVP. Fig. 1 shows portions of the matrix-assisted laser desorption/ionization (MALDI) mass spectra of the Au:PVP, recorded using different apparatuses. Fig. 1(a) shows a negative-ion MALDI mass spectrum measured using a linear time-of-flight (TOF) mass spectrometer (AXIMA-CFR, Shimadzu) at relatively high laser fluence. We observed a series of $\mathrm{Au}_{n}{ }^{-}$clusters produced via desorption from the polymer stabilization, in agreement with previous results [12]. Fig. 1(b) shows a mass spectrum recorded using a TOF mass spectrometer with a nominal flight path of $>17 \mathrm{~m}$ using a spiral ion trajectory (JMS-S3000, JEOL) and minimal laser fluence for the measurements. Some mass peaks were observed in addition to those attributed to the $\mathrm{Au}_{n}{ }^{-}$clusters. These interdigitated mass peaks were assigned to $\mathrm{Au}_{n} \mathrm{Cl}_{m}{ }^{-}$ based on the isotope pattern analysis (inset of Fig. 1(b)), although $\mathrm{Cl}$ was not detected in previous X-ray photoelectron spectroscopy (XPS) measurements of Au:PVP [13]. The com-

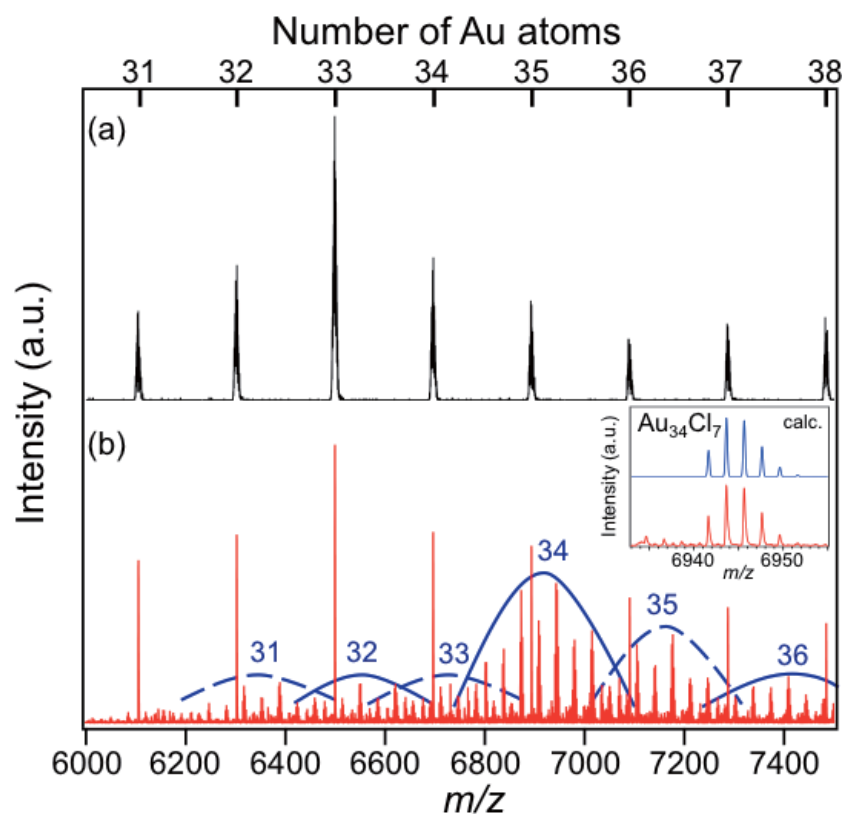

Fig. 1. Representative negative-ion MALDI mass spectra for Au:PVP, recorded using a lower-resolution apparatus at a relatively high laser fluence (a), and a higher-resolution apparatus at a low laser fluence (b). The inset shows the experimental (bottom) and simulated (top) isotopically resolved mass peaks for $\mathrm{Au}_{34} \mathrm{Cl}_{7}$. plete high-resolution mass spectra are shown in Fig. 2(a). Interestingly, the $\mathrm{Cl}$ adsorbates were observed mainly on $\mathrm{Au}$ clusters with sizes of $n=34$ and 43. Fig. 3(a) and (e) represents the number distribution of $\mathrm{Cl}$ adsorbates on the $\mathrm{Au}_{34}$ and $\mathrm{Au}_{43}$, respectively. On average, 7-9 $\mathrm{Cl}$ atoms were adsorbed on the $\mathrm{Au}_{34}$ and $\mathrm{Au}_{43}$. Weak even-odd oscillations were found in the distributions. The $\mathrm{Cl}$ adducts did not disappear, even after repeated deionizations performed using centrifugation. These results demonstrated for the first time that $\mathrm{Cl}$ atoms were adsorbed on the exposed surface of PVP-stabilized Au clusters. The adsorption of $\mathrm{Cl}$ on Au:PVP may not be surprising, given that $\mathrm{Cl}$ atoms from synthetic precursors are commonly observed in phosphine-protected $\mathrm{Au}$ clusters such as $\left[\mathrm{Au}_{11}\left(\mathrm{PPh}_{3}\right)_{8} \mathrm{Cl}_{2}\right] \mathrm{Cl}, \mathrm{Au}_{11}\left(\mathrm{PPh}_{3}\right)_{7} \mathrm{Cl}_{3}$, and $\mathrm{Au}_{55}\left(\mathrm{PPh}_{3}\right)_{12} \mathrm{Cl}_{6}$ [14-16]. Additionally, halide ions such as $\mathrm{Cl}^{-}, \mathrm{Br}^{-}$, or $\mathrm{I}^{-}$can be strongly adsorbed on metal surfaces [17-19], and their adsorption onto specific facets has been used to fabricate anisotropic nanostructures such as rods, wires, and plates [20,21]. Halides may modulate the electronic structure of the Au clusters by removing electronic charges [22]. Hence, the observations reported here raised a concern that these overlooked $\mathrm{Cl}$ adsorbates sterically and/or electronically affected the catalysis of the Au clusters.

The effects of the halogen adsorbates on the catalysis of Au:PVP were studied using the aerobic oxidation of benzyl alcohol as a model reaction. The amount and variety of halogen adsorbates were changed by mixing an aqueous solution of $\mathrm{KX}$ ( $\mathrm{X}=\mathrm{Cl}, \mathrm{Br}, \mathrm{I}$ ) with the hydrosol of Au:PVP prepared from

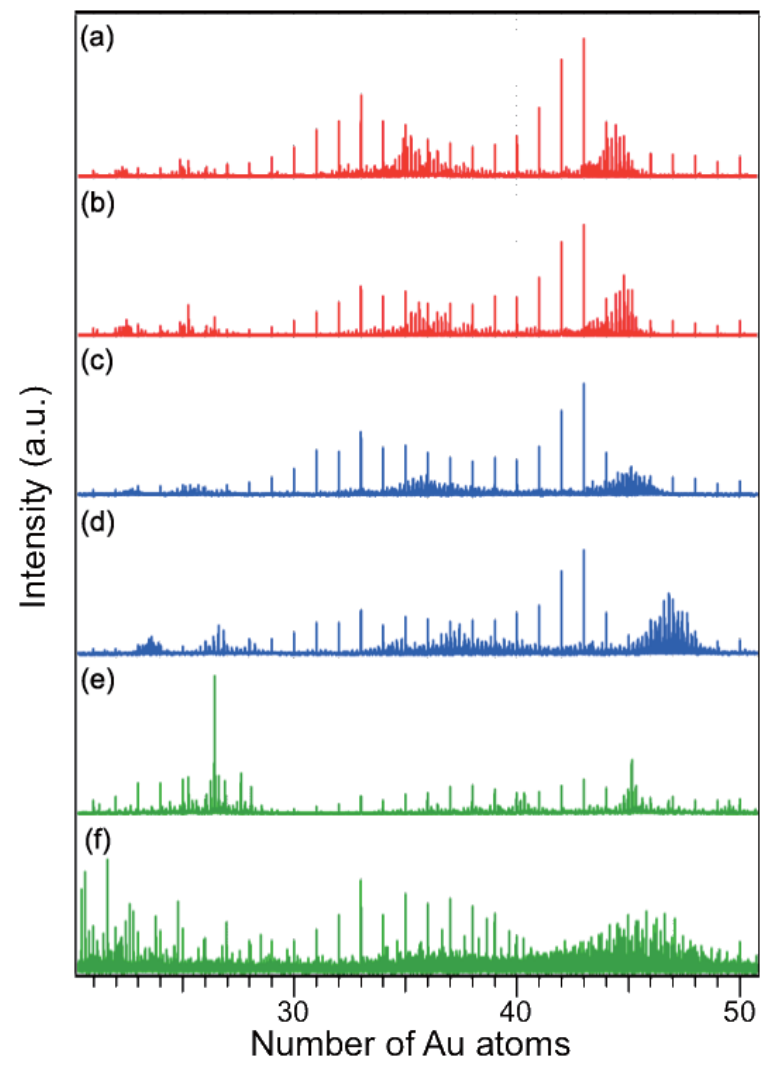

Fig. 2. Representative negative-ion MALDI mass spectra for six samples of Au:PVP. (a) Au:PVP(X-0); (b) Au:PVP(Cl-10), (c) Au:PVP(Br-5), (d) Au:PVP(Br-10), (e) Au:PVP(I-5); (f) Au:PVP(I-10). 

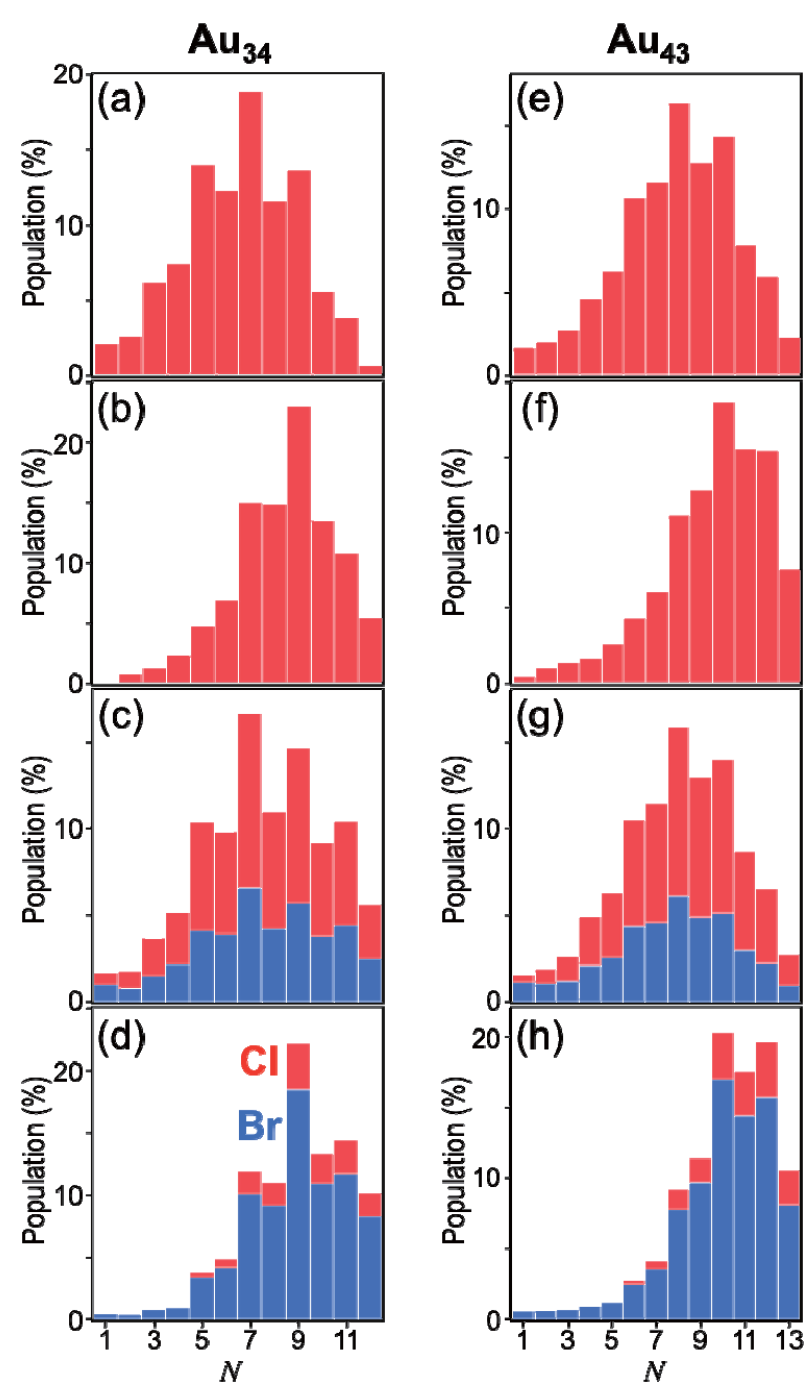

Fig. 3. Number distributions of $\mathrm{Cl}$ (red bars) and $\mathrm{Br}$ (blue bars) adsorbates. (a) Au:PVP(X-0), (b) Au:PVP(Cl-10), (c) Au:PVP(Br-5), and (d) $\mathrm{Au}: \mathrm{PVP}(\mathrm{Br}-10)$ for $\mathrm{Au}_{34}$; (e) $\mathrm{Au}: \mathrm{PVP}(\mathrm{X}-0)$, (f) $\mathrm{Au}: \mathrm{PVP}(\mathrm{Cl}-10)$, (g) $\mathrm{Au}: \mathrm{PVP}(\mathrm{Br}-5)$, and (h) Au:PVP(Br-10) for $\mathrm{Au}_{43}$.

$\mathrm{HAuCl}_{4}$. The molar ratio $(x)$ of $\mathrm{KX}$ with respect to the Au clusters, calculated assuming a cluster size of 40 , was varied from 5 to 20. The cluster samples obtained after deionization (achieved via centrifugal ultrafiltration with water) are referred to as Au:PVP(X- $x)(\mathrm{X}=\mathrm{Cl}, \mathrm{Br}, \mathrm{I})$ hereafter. According to this notation, the as-prepared Au:PVP clusters can be described as Au:PVP(X-0). The amount of halogen atoms adsorbed on the $\mathrm{Au}: \mathrm{PVP}(\mathrm{X}-\mathrm{x})$ was probed using MALDI mass analysis. Fig. 2 shows the negative-ion MALDI mass spectra for the $\mathrm{Au}: \mathrm{PVP}(\mathrm{X}-\mathrm{x})$. In addition to $\mathrm{Au}_{n}{ }^{-}, \mathrm{Au}_{n} \mathrm{Cl}_{m}{ }^{-}$clusters were observed for Au:PVP(X-0) and Au:PVP(Cl-10) (Fig. 2(a) and (b)), and $\mathrm{Cl}$ - and $\mathrm{Br}$-containing $\mathrm{Au}_{n} \mathrm{Cl}_{m} \mathrm{Br}^{-}$were observed in the mass spectra of Au:PVP(Br- $x$ ) (Fig. 2(c) and (d)). The $\mathrm{Au}_{n}{ }^{-}$size distributions did not change appreciably after the reaction with $\mathrm{KCl}$ or $\mathrm{KBr}$. A close inspection of Fig. 2(a)-(d) revealed that $\mathrm{Cl}$ and $\mathrm{Br}$ were adsorbed preferentially on the $\mathrm{Au}_{34}$ and $\mathrm{Au}_{43}$ clusters. In contrast, the mass spectra of Au:PVP(I-5) and $A u: P V P(I-10)$ showed significantly different patterns (Fig. 2(e) and (f)). The populations of smaller Au clusters were enhanced by the reaction with KI, suggesting that the Au clusters were converted to smaller clusters by etching with $\mathrm{I}^{-}[23,24]$. These reactivity trends were consistent with the order of the bond strength with the Au surface: $\mathrm{I}^{-}>\mathrm{Br}^{-}>\mathrm{Cl}^{-}[19,25]$. The MALDI mass analysis indicated that the Au cluster size for Au:PVP did not change appreciably after treatment with aqueous $\mathrm{KCl}$ or $\mathrm{KBr}$ solutions (Fig. 2(a)-(d)). The size of the Au:PVP clusters before and after the treatment with aqueous $\mathrm{KCl}$ or $\mathrm{KBr}$ solutions was also examined using transmission electron microscopy (TEM) and ultraviolet-visible (UV-vis) spectroscopy. The TEM images and size distributions for Au:PVP(Cl-10) and Au:PVP(Br-10) (Fig. 4(a)) indicated that the Au:PVP(X-0) size $(1.2 \pm 0.3 \mathrm{~nm})$ was retained during the reaction with $\mathrm{KX}(\mathrm{X}=\mathrm{Cl}$, $\mathrm{Br}$ ). The UV-vis spectra (Fig. 4(b)) also confirmed the retention of the Au cluster size.

The number distributions of halogens were examined based on the MALDI mass spectra, with a focus on Au:PVP(X-0), $\mathrm{Au}: \mathrm{PVP}(\mathrm{Cl}-10), \mathrm{Au}: \mathrm{PVP}(\mathrm{Br}-5)$, and $\mathrm{Au}: \mathrm{PVP}(\mathrm{Br}-10)$. It is interesting to note that $\mathrm{Cl}$ and $\mathrm{Br}$ were adsorbed preferentially on $\mathrm{Au}_{34}$ and $\mathrm{Au}_{43}$, as in the case of $\mathrm{Au}: \mathrm{PVP}(\mathrm{X}-0)$. The population $\left(I_{n, N}\right)$ of the $\mathrm{Au}_{n}(n=34$ or 43 ) clusters containing halogens with the total number $N$ was calculated according to the following equation:

$$
I_{n, N}=\sum_{m, l}^{m+l=N} I\left(A u_{n} C l_{m} B r_{l}^{-}\right) / \sum_{m, l}^{\substack{m, l \geq 0 \\ m+l \neq 0}} I\left(A u_{n} C l_{m} B r_{l}^{-}\right)
$$

where $m$ and $l$ represent the number of $\mathrm{Cl}$ and $\mathrm{Br}$, respectively, and $I\left(\mathrm{Au}_{n} \mathrm{Cl}_{m} \mathrm{Br}_{l}^{-}\right)$indicates the intensity of the $\mathrm{Au}_{n} \mathrm{Cl}_{m} \mathrm{Br}^{-}$mass peak. For example, $I_{34,2}$ was calculated by dividing the total ion intensities of $\mathrm{Au}_{34} \mathrm{Cl}_{2}{ }^{-}, \mathrm{Au}_{34} \mathrm{ClBr}^{-}$, and $\mathrm{Au}_{34} \mathrm{Br}_{2}{ }^{-}$by those of $\mathrm{Au}_{34} \mathrm{Cl}_{m} \mathrm{Br}^{-}$with $m, l \geq 0$ and $m+l \neq 0$. The populations of $I_{34, N}$ and $I_{43, N}$ are plotted as a function $N$ in Fig. 3. The reaction with $\mathrm{KCl}$ increased the number of $\mathrm{Cl}$ adsorbates (Fig. 3(b) and (f)).

(a)
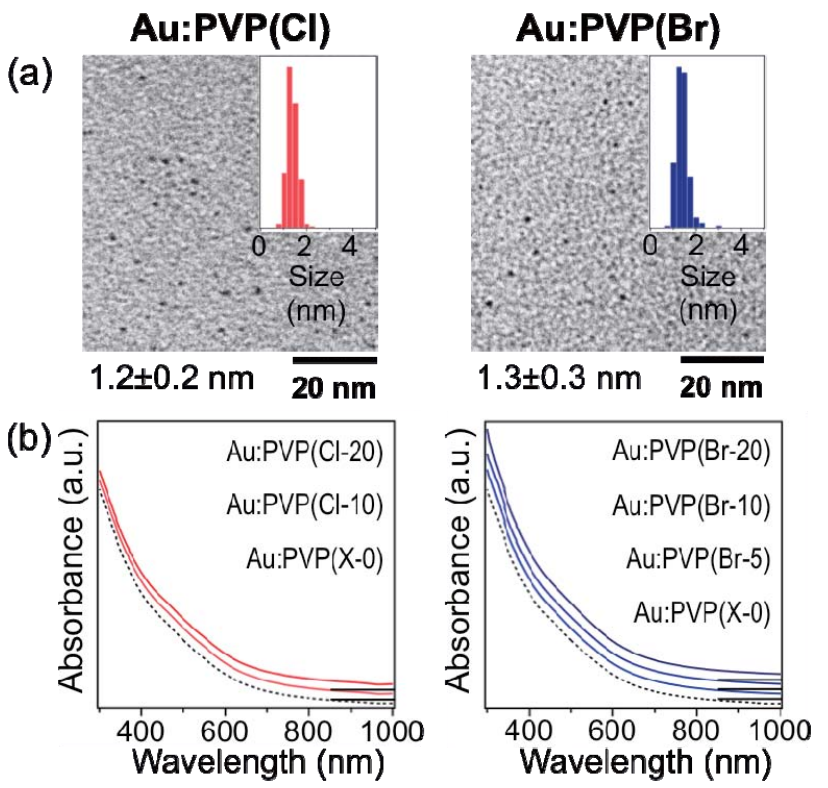

Fig. 4. (a) Representative TEM images and size distributions for Au:PVP(Cl-10) and Au:PVP(Br-10). (b) UV-vis absorption spectra for $\mathrm{Au}: \mathrm{PVP}(\mathrm{Cl}-x)$ and $\mathrm{Au}: \mathrm{PVP}(\mathrm{Br}-x)$. 
The addition of 5 eq. of $\mathrm{KBr}$ to Au:PVP caused nearly half of $\mathrm{Cl}$ adsorbates to be replaced with $\mathrm{Br}$ (Fig. 3(c) and (g)). In $\mathrm{Au}: \mathrm{PVP}(\mathrm{Br}-10)$, the originally adsorbed $\mathrm{Cl}$ atoms were replaced almost completely with Br (Fig. 3(d) and (h)). These results demonstrate that $\mathrm{Br}$ was bound more strongly to the Au clusters than $\mathrm{Cl}$, as previously reported for the Au surface $[19,25]$.

The electronic structure of Au:PVP(X-0) and $\mathrm{Au}: \mathrm{PVP}(\mathrm{Br}-160)$ was analyzed using XPS (Fig. 5). The binding energies of $\mathrm{Au} 4 f_{7 / 2}$ for Au:PVP(X-0) and Au:PVP(Br-160) were determined to be 82.6 and $82.7 \mathrm{eV}$, respectively. These values were slightly smaller than that of bulk gold $(84.0 \mathrm{eV})$ due to the electron donation from PVP $[8,26]$, but were similar to each other. The electron affinities of the bare $\mathrm{Au}_{n}$ clusters with $n \approx$ $30-40$ were determined to be in the range of 3.3-4.2 eV, using photoelectron spectroscopy $[27,28]$. These electron affinities of the $\mathrm{Au}_{n}$ clusters $(n \approx 30-40)$ were comparable to those of the halogens (3.61, 3.36, and $3.06 \mathrm{eV}$ for $\mathrm{Cl}, \mathrm{Br}$, and I, respectively). This suggested that the electronic states of the Aun clusters $(n \approx$ 30-40) were not significantly affected by the halogen adsorbates; this was in sharp contrast to the smaller Au clusters, where the halogens acted as electron acceptors [14-16,22].

The catalytic properties of Au:PVP $(\mathrm{X}-x)(\mathrm{X}=\mathrm{Cl}$ and $\mathrm{Br})$ were evaluated using the aerobic oxidation of benzyl alcohol in air as a test reaction (Table 1) to reveal the effect of the $\mathrm{Cl}$ and $\mathrm{Br}$ adsorbates on the catalysis of the Au clusters. The effect of I adsorbates was not evaluated, because the cluster sizes of $A u: P V P(I-x)$ were significantly different from that of Au:PVP(X-0) (Fig. 2(e) and (f)). Benzyl alcohol (25.9 $\mu \mathrm{L}, 0.25$ mmol), $\mathrm{K}_{2} \mathrm{CO}_{3}$ (103.7 $\mathrm{mg}, 0.75 \mathrm{mmol}$ ), and $\mathrm{H}_{2} \mathrm{O}(5 \mathrm{~mL})$ were mixed in a test tube. The hydrosol of Au:PVP(X-x) $(0.5 \mathrm{mmol} / \mathrm{L}$, $10 \mathrm{~mL}, 2$ atom\%) was then added to the mixed solution. The reaction mixture was stirred vigorously at $300 \mathrm{~K}$ for $1 \mathrm{~h}$, and then quenched with $1 \mathrm{~mol} / \mathrm{L} \mathrm{HCl}$. The products were extracted with ethyl acetate, and analyzed by gas chromatography. The catalysis results for Au:PVP(X- $x)$ are summarized in Table 1, and the conversions are shown as bar graphs in Fig. 6. These results demonstrated that the effects of $\mathrm{Cl}$ and $\mathrm{Br}$ on the catalysis were very different. The catalytic activity of Au:PVP(Br- $x)$ gradually decreased with increasing $x$, while that of

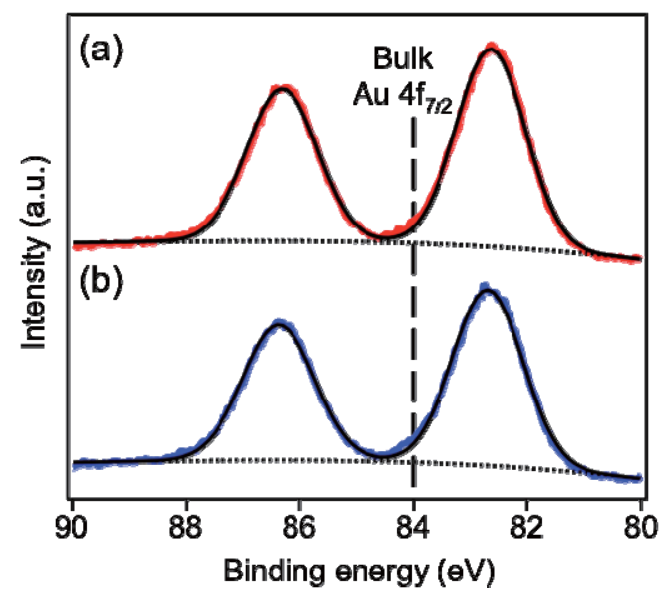

Fig. 5. Photoelectron spectra for Au:PVP(X-0) (a) and Au:PVP(Br-160) (b).
Table 1

Catalytic properties of Au:PVP(X-x) for the aerobic oxidation of benzyl alcohol.

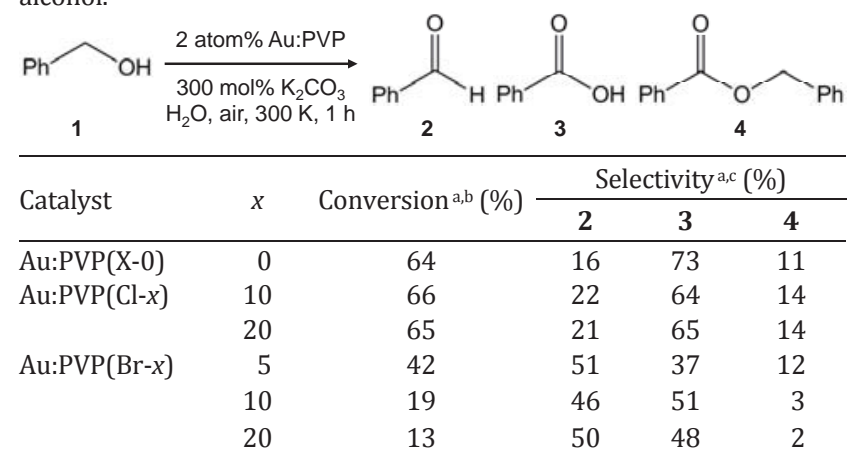

Reaction conditions: $\mathrm{PhCH}_{2} \mathrm{OH}(25.9 \mu \mathrm{L}, 0.25 \mathrm{mmol}), \mathrm{K}_{2} \mathrm{CO}_{3}(103.7 \mathrm{mg}$, $0.75 \mathrm{mmol})$, Au:PVP (0.5 mmol/L, $10 \mathrm{~mL}, 2$ atom\%), $\mathrm{H}_{2} \mathrm{O}(5 \mathrm{~mL})$, air pressure $1 \mathrm{~atm}$, temperature $300 \mathrm{~K}$, reaction time $1 \mathrm{~h}$.

${ }^{a}$ Determined by gas chromatography.

b Defined as the ratio of the amount of $\mathbf{1}$ consumed in the oxidation reaction to the amount of $\mathbf{1}$ at the initial time.

cDefined as the ratio of $\mathbf{1}$ converted to the corresponding products.

Au:PVP(Cl- $x)$ did not change with respect to $x$. This result reflected the different adsorption strengths of $\mathrm{Cl}$ and $\mathrm{Br}$. Although the $\mathrm{Cl}$ adsorbates could not be removed, even using repeated centrifugal ultrafiltration, they were desorbed during the catalytic reaction; elemental analysis showed that the amount of $\mathrm{Cl}$ for $A u: P V P(X-0)$ was reduced from 0.32 to $<0.01 \mathrm{wt} \%$ after catalytic usage under the conditions shown in Table 1 . This result suggested that benzyl alkoxide produced under basic conditions replaced the $\mathrm{Cl}$ adsorbate for the subsequent oxidation reaction. Therefore, the catalytic activity was retained even when the amount of $\mathrm{Cl}$ adsorbates is increased. In contrast, the reaction was retarded significantly by the $\mathrm{Br}$ adsorbates, suggesting that they were not removed efficiently by the benzyl alkoxide. Because the electronic state of the Au clusters was not altered appreciably (Fig. 5) by the adsorption of $\mathrm{Br}$, the decreased conversion at larger amounts of $\mathrm{Br}$ adsorbates could be explained by the steric blocking of the active sites.

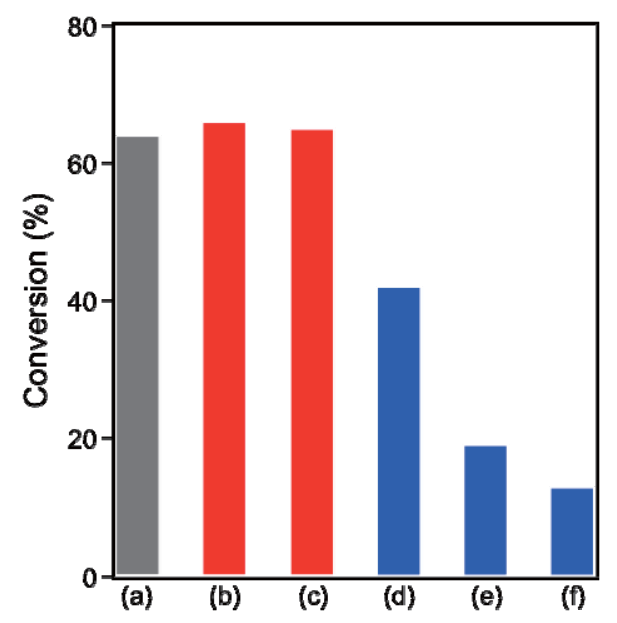

Fig. 6. Catalytic activity of Au:PVP(X-0) (a), Au:PVP(Cl-10) (b), Au:PVP(Cl-20) (c), Au:PVP(Br-5) (d), Au:PVP(Br-10) (e), and $\mathrm{Au}: \mathrm{PVP}(\mathrm{Br}-20)(\mathrm{f})$. 
The determination of the distribution of cluster compositions in the original Au:PVP(X-0) sample based on the MALDI mass spectra (Figs. 1(b) and 2(a)) was a formidable task. This was because MALDI mass spectra are typically affected by the distribution of the cluster compositions in the sample, and by their ionization efficiency and fragmentation process, which depend on the composition of the clusters. Nevertheless, the preferential observation of $\mathrm{Au}_{34} \mathrm{Cl}_{m}{ }^{-}$and $\mathrm{Au}_{43} \mathrm{Cl}_{m}{ }^{-}$suggested that the $\mathrm{Au}_{34} \mathrm{Cl}_{m}$ and $\mathrm{Au}_{43} \mathrm{Cl}_{m}$ clusters in their neutral form dominated in the Au:PVP(X-0) sample. The special stability of $\mathrm{Au}_{34} \mathrm{X}_{m}$ could be explained by the closure of the electronic shell with 34 valence electrons $[27,28]$ if we assumed that the electron transfer from $\mathrm{Au}_{34}$ to $\mathrm{Cl}$ was negligibly small. However, the origin of the efficient formation of $\mathrm{Au}_{43} \mathrm{X}_{m}$ is currently an open question [12]. The significant reduction in the catalytic activity when $\mathrm{Cl}$ was replaced with $\mathrm{Br}$ indicated that magic $\mathrm{Au}_{n} \mathrm{Cl}_{m}$ clusters $(n=34,43)$ in Au:PVP(X-0) made an essential contribution to the catalytic activity. Further investigation is needed to determine why the magic-sized Au clusters were catalytically reactive.

In summary, we demonstrated the adsorption of $\mathrm{Cl}$ atoms on Au clusters stabilized by PVP using mass spectrometry, and investigated their effect on the catalytic properties. The catalytic activity of Au:PVP was not affected by the presence of $\mathrm{Cl}$, but it was significantly suppressed by the $\mathrm{Br}$ adsorbates. This difference was attributed to the different binding strengths to gold. A substantial reduction in the catalysis was observed when the $\mathrm{Cl}$ was replaced with $\mathrm{Br}$ on the Au clusters, suggesting that magic-sized $\mathrm{Au}_{n}$ clusters $(n=34,43)$ dominantly acted as catalysts.

\section{Acknowledgments}

We thank Prof. Hiroshi Nishihara (The University of Tokyo) for providing us with access to the TEM apparatus.

\section{References}

[1] M. Haruta, N. Yamada, T. Kobayashi, S. Iijima, J. Catal., 1989, 115,
301-309.

[2] M. Haruta, Chem. Rec., 2003, 3, 75-87.

[3] A. Stephen, K. Hashmi, G. J. Hutchings, Angew. Chem. Int. Ed., 2006, 45, 7896-7936.

[4] Y. Liu, H. Tsunoyama, T. Akita, S. Xie, T. Tsukuda, ACS Catal., 2011, 1, 2-6.

[5] H. Tsunoyama, H. Sakurai, T. Tsukuda, Chem. Phys. Lett., 2006, 429, 528-532.

[6] S. Yamazoe, K. Koyasu, T. Tsukuda, Acc. Chem. Res., 2014, 47, 816-824.

[7] A. Taketoshi, M. Haruta, Chem. Lett., 2014, 43, 380-387.

[8] H. Tsunoyama, N. Ichikuni, H. Sakurai, T. Tsukuda, J. Am. Chem. Soc., 2009, 131, 7086-7093.

[9] T. Yoskamtorn, S. Yamazoe, R. Takahata, J. Nishigaki, A. Thivasasith, J. Limtrakul, T. Tsukuda, ACS Catal., 2014, 4, 3696-3700.

[10] Y. Wang, X. K. Wan, L. T. Ren, H. F. Su, G. Li, S. Malola, S. C. Lin, Z. C. Tang, H. Häkkinen, B. K. Teo, Q. M. Wang, N. F. Zheng, J. Am. Chem. Soc., 2016, 138, 3278-3281.

[11] H. Tsunoyama, N. Ichikuni, T. Tsukuda, Langmuir, 2008, 24, 11327-11330.

[12] H. Tsunoyama, T. Tsukuda, J. Am. Chem. Soc., 2009, 131, 18216-18217.

[13] H. Tsunoyama, H. Sakurai, N. Ichikuni, Y. Negishi, T. Tsukuda, Langmuir, 2004, 20, 11293-11296.

[14] G. Schmid, Chem. Rev., 1992, 92, 1709-1727.

[15] L. C. McKenzie, T. O. Zaikova, J. E. Hutchison, J. Am. Chem. Soc., 2014, 136, 13426-13435.

[16] K. Konishi, Struct. Bonding, 2014, 161, 49-86.

[17] J. Lipkowski, Z. Shi, A. Chen, B. Pettinger, C. Bilger, Electrochim. Acta., 1998, 43, 2875-2888.

[18] A. Chen, Z. Shi, D. Bizzotto, J. Lipkowski, B. Pettinger, C. Bilger, J. Electroanal. Chem., 1999, 467, 342-353.

[19] O. M. Magnussen, Chem. Rev., 2002, 102, 679-726.

[20] M. R. Langile, M. L. Personick, J. Zhang, C. A. Mirkin, J. Am. Chem. Soc., 2012, 134, 14542-14554.

[21] S. E. Lohse, N. D. Burrows, L. Scarabelli, L. M. Liz-Marzan, C. J. Murphy, Chem. Mater., 2014, 26, 34-43.

[22] M. Walter, J. Akola, O. Lopez-Acevedo, P. D. Jadzinsky, G. Calero, C. J. Ackerson, R. L. Whetten, H. Grönbeck, H. Häkkinen, Proc. Natl. Acad. Sci. USA, 2008, 105, 9157-9162.

[23] M. Grzelczak, A. Sanchez-Iglesias, B. Rodriguez-Gonzalez, R. Alvarez-Puebla, J. Perez-Juste, L. M. Liz-Marzan, Adv. Funct. Mater.,

\section{Graphical Abstract}

Chin. J. Catal., 2016, 37: 1656-1661 doi: 10.1016/S1872-2067(16)62501-9

\section{Halogen adsorbates on polymer-stabilized gold clusters: Mass spectrometric detection and effects on catalysis}

Ryo Ishida, Setsuka Arii, Wataru Kurashige, Seiji Yamazoe, Kiichirou Koyasu, Yuichi Negishi, Tatsuya Tsukuda*

The University of Tokyo; Kyoto University; Tokyo University of Science

The effect of halogen adsorbates on the oxidation catalysis of gold clusters was studied by monitoring the number and variation of halogens adsorbed using mass spectrometry.

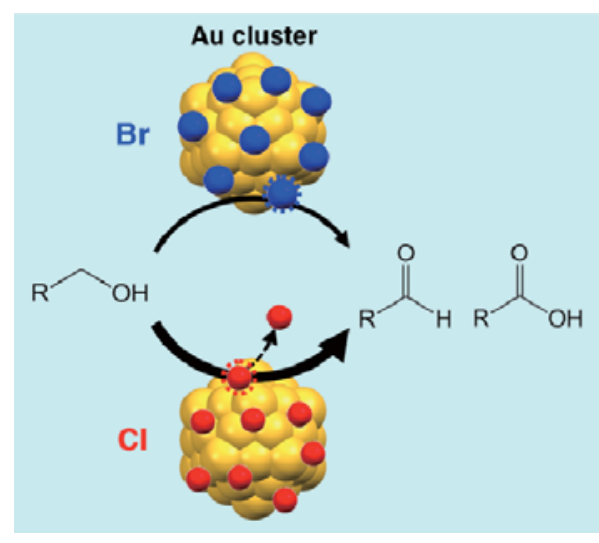


2008, 18, 3780-3786.

[24] T. Soejima, N. Kimizuka, J. Am. Chem. Soc., 2009, 131, 14407-14412.

[25] W. X. Niu, S. L. Zheng, D. W. Wang, X. Q. Liu, H. J. Li, S. Han, J. N. Chen, Z. Y. Tang, G. B. Xu, J. Am. Chem. Soc., 2009, 131, 697-703.
[26] M. Okumura, Y. Kitagawa, T. Kawakami, M. Haruta, Chem. Phys. Lett., 2008, 459, 133-136.

[27] K. J. Taylor, C. L. PettietteHall, O. Cheshnovsky, R. E. Smalley, J. Chem. Phys., 1992, 96, 3319-3329.

[28] L. M. Wang, L. S. Wang, Nanoscale, 2012, 4, 4038-4053.

\title{
聚合物稳定的金簇合物上卤素吸附质：质谱检测及其对催化的影响
}

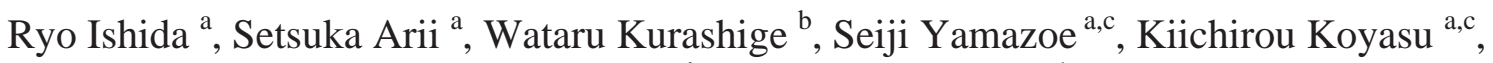 \\ Yuichi Negishi $^{\text {b }}$, Tatsuya Tsukuda ${ }^{\text {a,c,* }}$ \\ a东京大学理学院化学系, 东京113-0033, 日本 \\ b东京理科大学理学部应用化学系, 东京162-8601, 日本 \\ ‘京都大学触媒·电池元素战略研究基地, 京都615-8520, 日本
}

摘要: 聚(N-乙烯基-2-吡咯烷酮)稳定的金簇合物(Au:PVP)的质谱结果表明, 来源于合成前驱体的 $\mathrm{Cl}$ 吸附质主要存在于 $\mathrm{Au}_{34}$ 和 $\mathrm{Au}_{43}$ 簇合物上. 金簇合物上 $\mathrm{Cl}$ 吸附质的数量不影响其催化有氧苯甲醇氧化性能, 表明 $\mathrm{Cl}$ 原子与 $\mathrm{Au}$ 簇合物间存在较弱的键

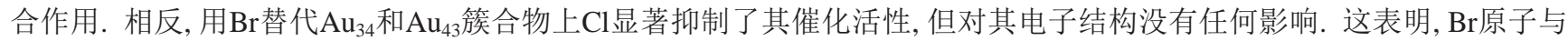
金簇合物的键合较强, 在空间上堵塞了活性位. 因Br吸附质而导致活性显著下降表明, $\mathrm{Au}_{34}$ 和 $\mathrm{Au}_{4}$ 簇合物对 $\mathrm{Au}: \mathrm{PVP}$ 催化活 性起主要贡献.

关键词：金簇合物；聚(N-乙烯基-2-吡咯烷酮); 卤素吸附质; 有氧醇氧化; 质谱

收稿日期: 2016-05-06. 接受日期: 2016-06-15. 出版日期: 2016-10-05.

*通讯联系人. 电话/传真: +81-3-5841-4363; 电子信箱: tsukuda@chem.s.u-tokyo.ac.jp

本文的英文电子版由Elsevier出版社在ScienceDirect上出版(http://www.sciencedirect.com/science/journal/18722067). 